\title{
İleri Glikasyon Son Ürünlerinin (AGEs) Öncüllerinin in Vitro Biyoerişilebilirliklerinin Bazı Gıdalarda Belirlenmesi
}

\author{
Mustafa Yaman ${ }^{1 *}$ \\ ${ }^{1 *}$ İstanbul Sabahattin Zaim University University, Faculty of Health Sciences, Department of Nutrition and Dietetics, İstanbul, Turkey, (ORCID: 0000-0001-9692- \\ 0204), mustafa.yaman@izu.edu.tr
}

(İlk Geliş Tarihi 2 Ağustos 2021 ve Kabul Tarihi 20 Eylül 2021)

(DOI: $10.31590 /$ ejosat.990119)

ATIF/REFERENCE: Yaman, M. (2021). İleri Glikasyon Son Ürünlerinin (AGEs) Öncüllerinin in Vitro Biyoerişilebilirliklerinin Bazı Gidalarda Belirlenmesi. Avrupa Bilim ve Teknoloji Dergisi, (27), 598-604.

$\ddot{O} \mathbf{z}$

İleri glikasyon son ürünlerinin (AGE'ler) öncüleri olan glioksal (GO) ve metilglioksal (MGO) hem gidalarda hemde insan vücudunda oluşabilmektedir. $\alpha$-dikarbonil bileşikleri olan GO ve MGO proteinlerin amino grubu ile reaksiyona girmesiyle AGE'ler oluşmaktadır. AGE bileşikleri kanser ve diyabet gibi birçok kronik hastalığın oluşum nedenleri arasında gösterilmektedir. AGE bileşikleri protein ve lipidlerin peroksidasyonu, Maillard reaksiyonları ve gıdaların işlenmesi sırasında oluşabilmektedir. Bu çalışmanın amacı, bisküvi, cips, kahvaltıllk gevrek ve süt ürünlerinde bulunan GO ve MGO'un in vitro gastrointestinal sindirim sisteminde biyoerişilebilirliğini belirlemek ve gıda çesitlerine göre oluşumlarını değerlendirmektir. Genel olarak bisküvi ve kahvaltılık gevrek örneklerinin GO ve MGO biyoerişilebilirliği \%100'ün üzerinde olduğu görülmüştür. Bisküvi örneklerinden glukoz miktarı yüksek olan örneğin GO biyoerişilebilirliği daha yüksek bulunmuştur. Cips örneklerinde ise GO’un biyoerişilebilirliği \%100'ün altında iken MGO biyoerişilebilirliği \%100'ün üzerinde bulunmuştur. Süt örneklerinde ise biyoerişilebilirlik hem GO hem de MGO'da \%100'ün altında olduğu görülmüş̧ür. Bu çalışmanın sonuçlarına göre yüksek yağ ve tuz in vitro ortamda lipidlerin peroksidasyonuna neden olabileceği ve bunun sonucunda $\alpha$-dikarbonil bileşiklerinin oluşabileceği düşünülmektedir. Gıdalardaki yağ, tuz ve serbest şeker içeriğinin azaltılması in vitro gastrointestinal sistemde daha düşük $\mathrm{GO}$ ve $\mathrm{MGO}$ oluşumunu sağlayabilir. Bu sonuçları desteklemek için yeni çalışmalara ihtiyaç vardır.

Anahtar Kelimeler: Glioksal, Metilglioksal, İleri glikasyon son ürünleri, Biyoerişilebilirlik, Gıda

\section{Determination of in Vitro Bioaccessibility of Precursors of Advanced Glycation End-Products (AGEs) in Some Foods}

\begin{abstract}
Glyoxal (GO) and methylglyoxal (MGO), which are the precursors of advanced glycation end products (AGEs), can occur both in food and in the human body. AGEs are formed by the reaction of $\alpha$-dicarbonyl compounds, GO and MGO, with the amino group of proteins. AGE compounds are shown as the cause of many chronic diseases such as cancer and diabetes. AGE compounds can be formed during oxidation of proteins and lipids, Maillard reactions, and food processing. The aim of this study is to determine the in vitro bioaccessibility of GO and MGO in biscuits, chips, breakfast cereals and milk products and to evaluate their formation according to food types. In general, GO and MGO bioaccessibility in biscuit and breakfast cereal samples were found to be above 100\%. GO bioaccessibility of the biscuit sample with high glucose was found to be higher than the other biscuit samples. In the chips samples, the bioaccessibility of GO was below $100 \%$, while the bioaccessibility of MGO was above $100 \%$. In milk samples, it was observed that both GO and MGO bioaccessibility were below $100 \%$. According to the results of this study, it is thought that high fat and salt may cause lipid peroxidation in in vitro and as a result, $\alpha$-dicarbonyl compounds may be formed. Reducing the fat, salt and free sugar content in foods may result in lower GO and MGO formation in the stimulated gastrointestinal tract. Further studies are needed to support these results.
\end{abstract}

Key words: Glyoxal, Methylglyoxal, Advanced glycation end products, Bioaccessibility, Food.

\footnotetext{
* Sorumlu Yazar: mustafa.yaman@izu.edu.tr
} 


\section{Giriş}

İleri glikasyon son ürünlerinin (AGE'ler) öncüleri hem gıdalarda hemde insan vücudunda oluşabilir (Uribarri vd. 2010; Sharma vd. 2015). AGE'ler protein ve lipidlerin oksidasyonu, Maillard reaksiyonları ve gıdaların işlenmesi sırasında oluşabilir. Maillard reaksiyonları indirgeyici şekerlerin bir karbonil grubu ile proteinlerin, peptitlerin, amino asitlerin ve nükleik asitlerin bir amino grubu arasındaki enzimatik olmayan reaksiyonlar ile başlar ve daha sonra kararsız Schiff bazlarına dönüşür. Bu kararsız ürünler moleküller arası düzenlemelerinden sonra daha kararlı Amadori/Heyns ürünlerine dönüşür. $\mathrm{Bu}$ ürünler glioksal $(\mathrm{GO})$, metilglioksal (MGO) ve 3-deoksiglukozon (3-DG) gibi oldukça reaktif $\alpha$-dikarbonil bileşiklerine dönüşür (Poulsen vd. 2013). Bu bileşikler lizin, arginin, histidin ve sistein gibi amino asitlerin amino grupları ile reaksiyona girer ve $\mathrm{N}-\varepsilon$-karboksimetillizin (CML), N- $\varepsilon$-karboksietillizin (CEL) ve pentosidin gibi AGE son ürünleri dönüşür (Henle 2005; Luevano- Contreras ve ChapmanNovakofski, 2010). GO ve MGO işlenmiş gıdalarda ve biyolojik sistemlerde en çok bulunan $\alpha$-dikarbonil bileşikleridir (Liu vd. 2011). GO ve MGO insan vücudunda glukozun oto-oksidasyonu, lipid peroksidasyonu ve poliol yolu sırasında ortaya çıkabilir (Luevano-Contreras ve Chapman-Novakofski, 2010). Maillard reaksiyon ürünleri bağırsak sistemleri tarafindan kısmen emilebilir. Yapılan klinik çalışmalarda Tip 2 diyabet hastalarının plazmalarında yüksek miktarlarda $\alpha$-dikarbonil bileşiklerinin olduğu bildirilmiştir. GO ve MGO bileşiklerinin pankreas hücrelerinde insülin proteininin amino gruplarına kovalent olarak bağlandığı ve AGE'lerin oluşumuna yol açtığ durumun ise insülin direncine neden olduğu ve hücresel glukoz alımını azalttı̆̆ı aynı çalışmada belirtilmiştir (Nowotny vd. 2015). Diyabet, alzheimer, parkinson, yaşlanma ve böbrek yetmezliği olan hastalarının dokularında MGO kaynaklı AGE bileşiklerinin yüksek seviyede olduğu bildirilmiştir (Rabbani ve Thornalley, 2014).

Gıdalardaki CML ve MGO miktarının pişirme yöntemi ve pişirme sıcaklığı ile ilişkili olduğu bildirilmiştir. Ayrıca besinlerdeki AGE miktarı ile yağ içeriği ve MGO düzeyi arasında önemli bir korelasyon olduğu da raporlanmıştır. Besinlerdeki en yüksek AGE bileşikleri cips, kraker ve kurabiye gibi yüksek yağ içeren gıdalarda bulunduğu birçok çalışmada ortaya koyulmuştur (Uribarri vd. 2010).

Genel olarak günlük diyetle alınan besin ögelerinin miktarları gıda kompozisyon veri tabanlarında ham ya da pişmiş gıda verilerinden elde edilmektedir. Yapılan birçok in vitro ve in vivo çalışmalarda göre besin ögelerinin biyoerişilebilirliğine bağlı olarak günlük diyetle alınan miktarın daha farklı olduğu bilinmektedir. $\mathrm{Bu}$ nedenle günlük diyetlerde besin ögelerinin miktarı hesaplanırken biyoerişilebilirliğine değerlendirilmelidir (Yaman vd. 2021). Maillard reaksiyon ürünlerinin in vitro ve in vivo ortamda biyoerişilebilirliği hakkında çok az sayıda çalışma bulunmaktadır. Patates kızartması ve cipslerde mide sindiriminden sonra akrilamid'in biyoerişilebilirliğinin arttığını bildirilmiştir (Sansano vd. 2017). Sirke örneklerinde ise GO ve MGO'nun in vitro biyoerişilebilirliğinin azaldığını bildirmiştir (Papetti vd. 2013). Soya sosunda ise GO ve MGO'nun in vitro biyoerişilebilirliğinin arttığını bildirmiştir (Papetti vd. 2014). Görüldüğü gibi farklı gıda çeşitlerine göre Maillard reaksiyon ürünlerinin biyoerişilebilirliğinde artış ve azalışlar olduğu görülmektedir. Bilindiği gibi işlenmiş gıdalar AGE bileşiklerinin oluşumuna yol açan yüksek miktarda GO ve MGO içermektedir.
İşlenmiş gıdalardaki GO ve MGO'nun in vitro biyoerişilebilirliğinin bilinmesi diyetle alınan son AGE miktarlarını belirlenmesi açısından önemli olacaktır. $\mathrm{Bu}$ araştırmanın amacı in vitro gastrointestinal sindirim sistemi kullanılarak bazı gidalarda bulunan GO ve MGO'nun biyoerişilebilirliğini belirlemek ve gıda çeşitlerine göre oluşumlarını değerlendirmektir.

\section{Materyal ve Metot}

\subsection{Materyal}

Glioksal, metilglioksal, metanol, asetonitril, sodyum asetat, 4-nitro-1,2-fenilendiamin, fruktoz, glukoz, sakkaroz, alfa-amilaz (1.5 U/mg), pepsin ( $\geq 250$ ünite/mg), pankreatin (8 x USP), lipaz (100-500 ünite/mg), $\mathrm{NaHCO}_{3}, \mathrm{CaCl}_{2} \cdot 2 \mathrm{H}_{2} \mathrm{O}, \mathrm{KCl}, \mathrm{NaCl}$, serum albümin (sığır), safra tuzları, üre, ürik asit ve müsin SigmaAldrich'ten (St. Louis, MO, ABD) temin edilmiştir.

\section{2. Örneklem}

Bu çalışmada kullanılan gıda örnekleri İstanbul'daki farklı marketlerden alınmıştır. Numunelerin içerikleri Tablo 1'de verilmiştir.

\subsection{GO ve MGO Ekstraksiyonu ve Türevlendirme}

Homojenize edilmiş $5 \mathrm{~g}$ numune $50 \mathrm{~mL}$ 'lik plastik falkon tüpü içine tartıldı ve $25 \mathrm{~mL}$ metanol ilave edildi. Numune $5 \mathrm{dk}$ vortekslendi ve 8000 rpm'de 5 dakika santrifüj edildi. $1 \mathrm{~mL}$ supernatant $10 \mathrm{~mL}$ 'lik cam tüp içine alındı ve üzerine $1 \mathrm{~mL}$ $\mathrm{CH}_{3} \mathrm{COONa}$ tamponu (0.1 M, pH: 3 ) ilave edildi. Daha sonra 0,5 $\mathrm{mL}$ türevlendirme solüsyonu (\%1 metanol içinde 4-nitro-1,2fenlendiamin) ilave edildi. Karışım $70{ }^{\circ} \mathrm{C}^{\prime}$ de 20 dakika inkübe edildi. Numuneler $0,45 \mu \mathrm{m}$ 'lık selüloz asetat filtresi kullanılarak süzüldü ve HPLC'ye enjekte edildi (Cengiz vd. 2020).

\subsection{GO ve MGO'nun ile HPLC Tayini}

GO ve MGO'nun kantitatif tayininde Shimadzu SPD-20A UV/VIS dedektörü (Shimadzu Corporation, Kyoto, Japonya) ile Shimadzu LC 20AT pompasından oluşan HPLC Sistemi kullanıld1. Ayırma işleminde Metanol:Su:Asetonitril'den (42:56:2 v/v/v) oluşan mobil faz kullanıldı ve akış hızı $1 \mathrm{~mL} / \mathrm{dk}$ olarak ayarlandı. Ayırma işleminde Inersil ODS-3 kolon kullanıldı ve dedektörün dalga boyu 254 nm'ye kolon firın sıcaklığı ise $30^{\circ} \mathrm{C}$ 'ye ayarland 1.

\section{5. Şeker Bileşenleri Ekstraksiyonu}

Homojenize edilmiş $5 \mathrm{~g}$ numune $50 \mathrm{~mL}$ 'lik falkon tüp içine tartıld1. Üzerine $25 \mathrm{~mL}$ deiyonize su ilave edildi ve vorteks kullanılarak 5 dakika ekstrakte edildi. Daha sonra hacim deiyonize su ile $50 \mathrm{~mL}$ 'ye tamamland 1 ve 8000 rpm'de 10 dakika santrifüj edildi (Richmond vd. 1981). Numuneler, 0,45 um'lik selüloz asetat filtresi ile süzüldü ve HPLC'ye enjekte edildi.

\section{6. Şeker Bileşenlerinin HPLC ile Tayini}

Şeker bileşenlerinin kantitatif tayininde Shimadzu RI-20A dedektörü (Shimadzu Corporation, Kyoto, Japonya) ile Shimadzu LC 20AT pompasından oluşan HPLC Sistemi kullanıldı. Ayırma işleminde Asetonitril'den ve deiyonize su'dan (80:20 v/v) oluşan mobil faz kullanıldı ve akış hızı $2 \mathrm{~mL} / \mathrm{dk}$ olarak ayarlandı. Ayırma işleminde Agilent $\mathrm{NH}_{2}, 250$ x $4.6 \mathrm{~mm}, 5 \mu \mathrm{m}$ kolon kullanıldı ve kolon firın sıcaklığı ise $40{ }^{\circ} \mathrm{C}^{\prime}$ ye ayarland. 


\subsection{GO ve MGO'nun in vitro Biyoerişilebilirliği}

Gıdalardaki GO ve MGO'nun biyoerişilebilirliği in vitro gastrointestinal sindirim sistemi kullanılarak belirlendi (Yaman vd. 2019). Tükürük, mide, ince bağırsak ve safra sıvısı Şekil l'de gösterildiği gibi hazırlandı.

Beş gram numune $50 \mathrm{~mL}$ 'lik falkon tüp içine tartıldı. Üzerine $5 \mathrm{~mL}$ tükürük sıvısı ilave edildi ve çalkalamalı su banyosunda 37
${ }^{\circ} \mathrm{C}$ 'de $5 \mathrm{dk}$ inkübe edildi. Daha sonra $10 \mathrm{~mL}$ mide sivisı ilave edildi ve çalkalamalı su banyosunda $37^{\circ} \mathrm{C}$ 'de $30 \mathrm{dk}$ inkübe edildi. Hazırlanan safra sivisindan $5 \mathrm{~mL}$ ilave edildi ve $\mathrm{pH}$ 7'ye ayarlandı. Üzerine ince bağırsak sıvısından $10 \mathrm{~mL}$ eklendi ve $37^{\circ} \mathrm{C}$ 'de çalkalama su banyosunda 2 saat inkübe edildi. Daha sonra son hacim deiyonize su ile $50 \mathrm{~mL}$ 'ye tamamlandı ve karışım 8000 rpm'de 5 dakika santrifüjlendi.

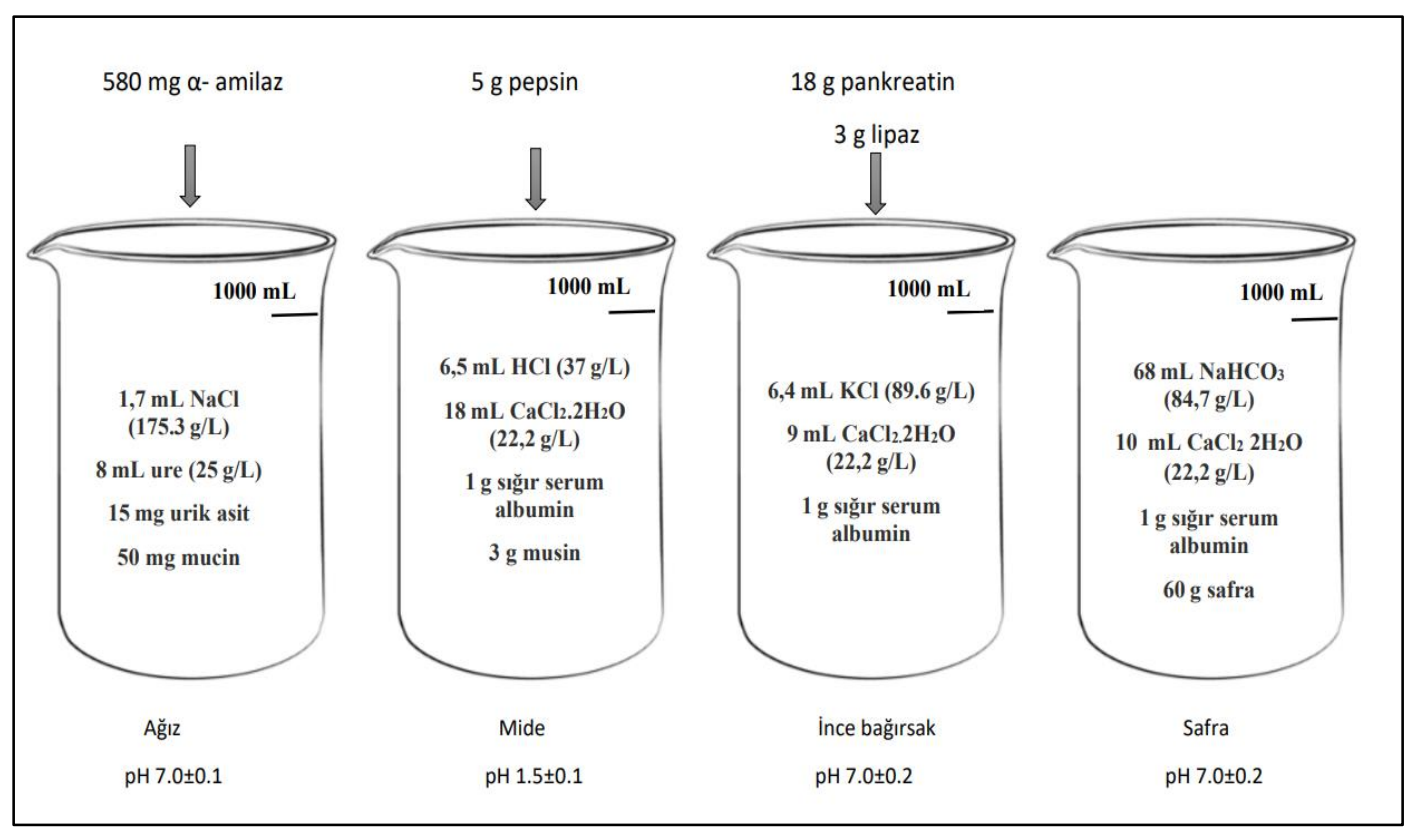

Şekil 1. In vitro insan sindirim modelinde kullanılan tükürük, mide, ince bağırsak ve safra sıvısının hazırlanışı.

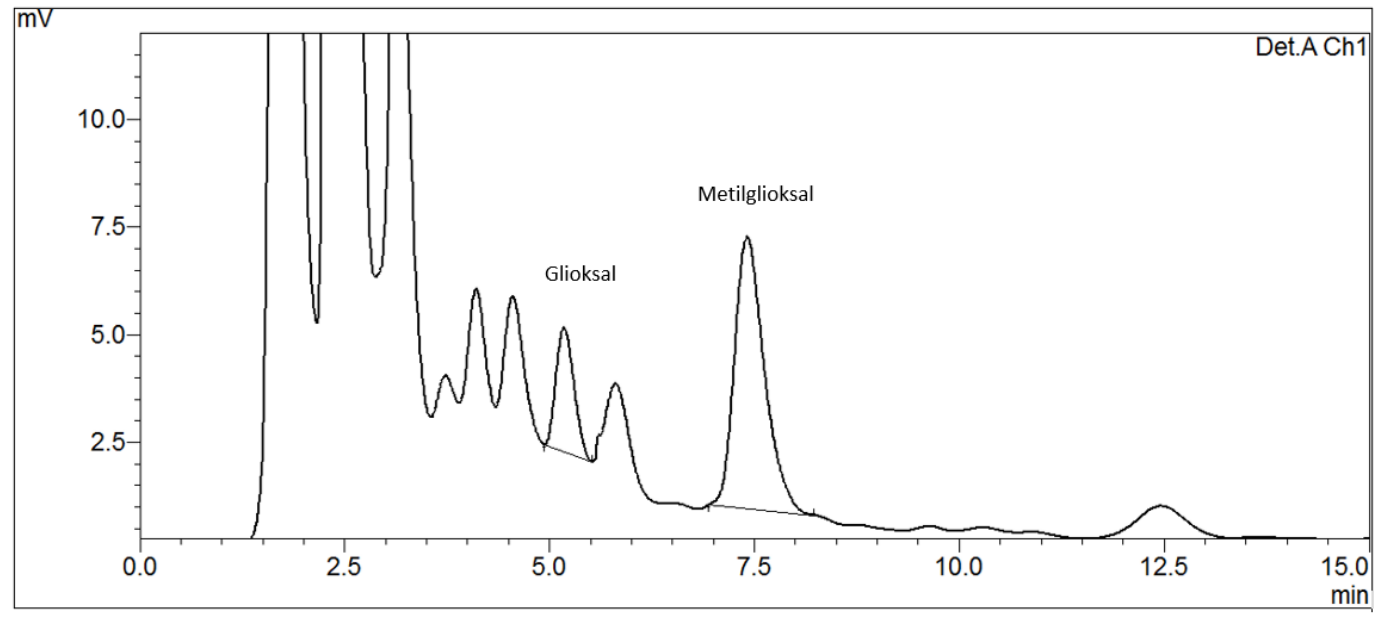

Şekil 2. Bisküvide glioksal (GO) ve metilglioksal (MGO) HPLC kromatogramı (örnek 1).

\section{Araştırma Sonuçları ve Tartışma}

GO ve MGO'un örnek HPLC kromatogramı (bisküvi) Şekil 2'de gösterilmektedir. Sindirimden önce ve sonra GO ve MGO'nun miktarı ve biyoerişilebilirlik bulguları Tablo 2'de gösterilmiştir. Numunelerin etiketleri üzerinde beyan edilen yağ miktarı ve analiz sonucunda elde edilen şeker bileşelenleri sonuçları Tablo 1'de gösterilmiştir. 
Tablo 1. Numunelerin beyan edilen yağ içerikleri, şeker bileşenleri miktarları ve içerikleri.

\begin{tabular}{llcccc}
\hline No Ürün adı & $\begin{array}{c}\text { Beyan edilen yağ miktarı } \\
(\mathrm{g} / 100 \mathrm{~g})\end{array}$ & $\begin{array}{c}\text { Fruktoz } \\
(\mathrm{g} / 100 \mathrm{~g})\end{array}$ & $\begin{array}{c}\text { Glukoz } \\
(\mathrm{g} / 100 \mathrm{~g})\end{array}$ & $\begin{array}{c}\text { Sakkaroz } \\
(\mathrm{g} / 100 \mathrm{~g})\end{array}$ \\
\hline 1 & Bisküvi, Lif Kepeği, Limon & 12,5 & $0,51 \pm 0.01$ & $3,38 \pm 0.05$ & $8,76 \pm 0,12$ \\
2 & Bisküvi, Tam Buğday, Yağı Azaltılmış & 10,8 & $0,61 \pm 0$ & $0,28 \pm 0.01$ & $2,19 \pm 0.06$ \\
3 & Bisküvi, Lif Kepeği, Karışık Meyve, Şekeri azaltılmı̧̧ & 13 & $0,47 \pm 0.02$ & $6,08 \pm 0,66$ & $0,68 \pm 0.01$ \\
4 & Biscuits, Black Seed Grass, Quinoa & 11 & $0,56 \pm 0.01$ & $0,79 \pm 0.01$ & $0,96 \pm 0$ \\
5 & Bisküvi, Çörek Otu, Kinoa & 17 & $0,51 \pm 0.01$ & $0,23 \pm 0$ & $16,64 \pm 0.54$ \\
6 & Bisküvi, Buğday unu & 9,6 & $1,52 \pm 0.03$ & $1,68 \pm 0,15$ & $16,76 \pm 0,62$ \\
7 & Gofret, findık & 29,11 & $0,02 \pm 0$ & $0,02 \pm 0$ & $6,81 \pm 0,05$ \\
8 & Bisküvi, Buğday unu & 21 & $0 \pm 0$ & $0 \pm 0$ & $28.16 \pm 0.78$ \\
9 & Cips, mısır, fistık & 31,7 & $0 \pm 0$ & $0 \pm 0$ & $0 \pm 0$ \\
10 & Cips, patates & 33,8 & $0 \pm 0$ & $0 \pm 0$ & $0 \pm 0$ \\
11 & Cips, mısır, peynir & 26,5 & $0 \pm 0$ & $0 \pm 0$ & $0 \pm 0$ \\
12 & Tahıl Gevreği, Çikolata & 4.8 & $0,08 \pm 0$ & $0,02 \pm 0$ & $11,01 \pm 022$ \\
13 & Tahıl Gevreği, Çikolata & 7 & $0,05 \pm 0$ & $0 \pm 0$ & $21,71 \pm 0.78$ \\
14 & Milk, UHT & 3,1 & $0 \pm 0$ & $0 \pm 0$ & $0 \pm 0$ \\
15 & Milk, UHT, kakao & 1,5 & $0 \pm 0$ & $0 \pm 0$ & $0 \pm 0$ \\
16 & Milk, UHT, çilek & 1,5 & $0 \pm 0$ & $0 \pm 0$ & $0 \pm 0$ \\
\hline
\end{tabular}

Ortalama değer $(\mathrm{n}=3)$ standart sapma ile verildi.

Bisküvi örneklerinde in vitro sindirimden öncesi ölçülen GO ve MGO miktarları sirasıyla 81 ile $169 \mu \mathrm{g} / 100 \mathrm{~g}$ ve 55 ile $607 \mu \mathrm{g} / 100$ $\mathrm{g}$ arasında değişmektedir. Sindirimden sonra ise GO ve MGO'nun biyoerişilebilirliği sırasıyla $\% 33$ ile $\% 236$, ve $\% 40$ ile $\% 114$ arasında bulunmuştur. Etiket üzerinde beyan edilen yağ miktarı 9,6 ile 29,11 g/100 g arasında değişmektedir. Sonuçlara bakıldığında bisküvilerdeki yağ içeriği ve biyoerişilebilirlik arasında anlamlı bir ilişki görülmemiş̧ir. Karışık meyveli bisküvi örneğinin diğer bisküvilere göre daha yüksek GO biyoerişilebilirliğine sahip olduğu görülmektedir. Diğer bisküvilerden farklı olarak bu bisküvide yüksek miktarda glukoz olduğuda Tablo 1'de görülmektedir. Hrynets vd. (2015) glukozamin, N-asetil-glukozamin ve glukozun $\mathrm{NH}_{3}$ 'ün bulunduğu in vitro ortamda $\alpha$-dikarbonil bileşiklerine dönüştüğünü bildirmiştir. Görüldüğü gibi bizim çalışmamızda da glukozun in vitro ortamda $\alpha$-dikarbonil bileşiklerine dönüştüğü düşünülmektedir. MGO'nun hem enzimatik olarak hem de enzimatik olmayan ortamda protein glikasyonu yoluyla oluşabileceği bildirilmiştir (O'Brien vd. 1998). Amrein vd. (2006) $\alpha$-dikarbonil bileşiklerinin oluşumları ile glukoz ve fruktoz arasında sakaroza göre daha yüksek bir korelasyon olduğunu bildirmiştir. Dolaysıyla bizim çalışmamızdaki bisküvilerde glukoz miktarının GO'nun in vitro biyoerişilebilirliğini etkilediği düşünülmektedir.

Cips örneklerinde in vitro sindirim öncesi ölçülen GO ve MGO miktarı sirasiyla 135 ve $142 \mu \mathrm{g} / 100 \mathrm{~g}$, ve 42 ve $69 \mu \mathrm{g} / 100$ $\mathrm{g}$ arasinda bulunmuştur. $\mathrm{GO}$ ve $\mathrm{MGO}^{\prime} u$ in vitro biyoerişilebilirliği sırasıly $\% 67$ ile $\% 86$, ve $\% 213$ ile $\% 392$ arasında bulunmuştur. Etkiket üzerinde beyan edilen yağ ve tuz içeriği 26,5 ile $33,8 \mathrm{~g} / 100 \mathrm{~g}$ arasında iken tuz içeriği 1,0 ile 1,5 $\mathrm{g} / 100 \mathrm{~g}$ arasındadır. Bu sonuçlardan görüldüğü gibi GO'nun in vitro biyoerişilebiliği \%100'ün altında iken MGO'nun biyoerişilebiliği \%100'ün üzerindedir. İşlenmiş gıdalardaki yağ miktarının $\alpha$-dikarbonil bileşiklerinin oluşumunu etkilediği bilinmektedir. Bizim çalışmamızdaki cipslerde MGO'nun in vitro biyoerişilebilirği \%100'ün üzerinde olmasının nedeni içeriğindeki yüksek yağ miktarınından kaynaklanmış olabileceği düşünülmektedir. Çünkü in vitro ortamda yağların oksidasyonu sonucu $\alpha$-dikarbonil bileşiklerinin oluştuğu bilinmektedir. Bunun yanında cipslerde belirli miktarda tuz içermektedir. Tuz içeriğinin MGO'nun biyoerişilebilirliğini in vitro ortamda arttırdığı da düşünülmektedir. 
Tablo 2. Sindirim öncesi ve sindirm sonrası GO ve MGO'nun miktarları ve biyoerişilebilirlikleri.

\begin{tabular}{ccccccc}
\hline & Sindirim Öncesi & Sindirim Sonras1 & Sindirim Öncesi & Sindirim Sonras1 & \multicolumn{2}{c}{ Biyoerişilebilirlik \% } \\
Örnek no & GO $(\mu \mathrm{g} / 100 \mathrm{~g})$ & $\mathrm{GO}(\mu \mathrm{g} / 100 \mathrm{~g})$ & $\mathrm{MGO}(\mu \mathrm{g} / 100 \mathrm{~g})$ & $\mathrm{MGO}(\mu \mathrm{g} / 100 \mathrm{~g})$ & $\mathrm{GO}$ & $\mathrm{MGO}$ \\
\hline 1 & $143 \pm 4^{\mathrm{a}}$ & $149 \pm 4^{\mathrm{a}}$ & $347 \pm 8^{\mathrm{a}}$ & $140 \pm 2^{\mathrm{b}}$ & $104 \pm 3$ & $40 \pm 1$ \\
2 & $160 \pm 6^{\mathrm{a}}$ & $128 \pm 5^{\mathrm{b}}$ & $55 \pm 2^{\mathrm{a}}$ & $59 \pm 3^{\mathrm{a}}$ & $80 \pm 3$ & $109 \pm 6$ \\
3 & $81 \pm 3^{\mathrm{a}}$ & $191 \pm 3^{\mathrm{b}}$ & $607 \pm 16^{\mathrm{a}}$ & $212 \pm 6^{\mathrm{b}}$ & $236 \pm 4$ & $35 \pm 1$ \\
4 & $156 \pm 5^{\mathrm{a}}$ & $52 \pm 3^{\mathrm{b}}$ & $101 \pm 4^{\mathrm{a}}$ & $115 \pm 6^{\mathrm{b}}$ & $33 \pm 2$ & $114 \pm 6$ \\
5 & $122 \pm 3^{\mathrm{a}}$ & $76 \pm 3^{\mathrm{b}}$ & $178 \pm 8^{\mathrm{a}}$ & $78 \pm 3^{\mathrm{b}}$ & $62 \pm 2$ & $44 \pm 2$ \\
6 & $169 \pm 5^{\mathrm{a}}$ & $202 \pm 8^{\mathrm{b}}$ & $211 \pm 9^{\mathrm{a}}$ & $220 \pm 6^{\mathrm{a}}$ & $119 \pm 4$ & $104 \pm 3$ \\
7 & $153 \pm 4^{\mathrm{a}}$ & $48 \pm 4^{\mathrm{b}}$ & $23 \pm 2^{\mathrm{a}}$ & $24 \pm 1^{\mathrm{a}}$ & $31 \pm 3$ & $103 \pm 4$ \\
8 & $113 \pm 3^{\mathrm{a}}$ & $92 \pm 3^{\mathrm{b}}$ & $167 \pm 5^{\mathrm{a}}$ & $102 \pm 3^{\mathrm{b}}$ & $81 \pm 2$ & $61 \pm 2$ \\
9 & $135 \pm 4^{\mathrm{a}}$ & $100 \pm 4^{\mathrm{b}}$ & $57 \pm 3^{\mathrm{a}}$ & $121 \pm 4^{\mathrm{b}}$ & $74 \pm 3$ & $213 \pm 6$ \\
10 & $141 \pm 4^{\mathrm{a}}$ & $121 \pm 5^{\mathrm{b}}$ & $42 \pm 2^{\mathrm{a}}$ & $163 \pm 6^{\mathrm{b}}$ & $86 \pm 4$ & $392 \pm 15$ \\
11 & $142 \pm 3^{\mathrm{a}}$ & $95 \pm 4^{\mathrm{b}}$ & $49 \pm 3^{\mathrm{a}}$ & $168 \pm 7^{\mathrm{b}}$ & $67 \pm 3$ & $344 \pm 14$ \\
12 & $169 \pm 3^{\mathrm{a}}$ & $370 \pm 6^{\mathrm{b}}$ & $65 \pm 3^{\mathrm{a}}$ & $137 \pm 4^{\mathrm{b}}$ & $220 \pm 3$ & $210 \pm 6$ \\
13 & $142 \pm 4^{\mathrm{a}}$ & $108 \pm 4^{\mathrm{b}}$ & $55 \pm 2^{\mathrm{a}}$ & $66 \pm 3^{\mathrm{b}}$ & $76 \pm 3$ & $121 \pm 6$ \\
14 & $62 \pm 3^{\mathrm{a}}$ & $11 \pm 1^{\mathrm{b}}$ & $19 \pm 2^{\mathrm{a}}$ & $7 \pm 1^{\mathrm{b}}$ & $17 \pm 1$ & $39 \pm 3$ \\
15 & $111 \pm 3^{\mathrm{a}}$ & $27 \pm 1^{\mathrm{b}}$ & $25 \pm 3^{\mathrm{a}}$ & $8 \pm 1^{\mathrm{b}}$ & $25 \pm 1$ & $30 \pm 2$ \\
16 & $114 \pm 4^{\mathrm{a}}$ & $11 \pm 1^{\mathrm{b}}$ & $43 \pm 3^{\mathrm{a}}$ & $8 \pm 1^{\mathrm{b}}$ & $10 \pm 1$ & $18 \pm 2$ \\
\hline
\end{tabular}

Ortalama değer $(\mathrm{n}=3)$ standart sapma ile verildi.

Kahvalt1lı gevrek örneklerinde in vitro sindirim öncesi ölçülen GO ve MGO miktarı sırasıyla 142 ile $169 \mu \mathrm{g} / 100 \mathrm{~g}$, ve 55 ile $65 \mu \mathrm{g} / 100 \mathrm{~g}$ arasında bulunmuştur. Tablo 1'de görüldüğü gibi kahvaltılık gevrek örneklerinde şeker olarak daha çok sakaroz bulunmaktadır. Etiket üzerinde beyan edilen yağ miktarları ile 4,8 ile $7,0 \mathrm{~g} / 100 \mathrm{~g}$ arasindadır. GO ve MGO'un in vitro biyoerişilebilirliği sırasıyla $\% 76$ ile $\% 220$, ve $\% 121$ ile $\% 210$ arasında bulunmuştur. İşlenmiş gıdalarda yüksek yağ içeriği GO ve MGO'nun miktarını arttırdığı bilinmektedir. Bilindiği gibi in vitro ortamda lipid peroksidasyonu sonucu GO ve MGO oluşabilmektedir. Kahvaltılık gevreklerde belirli miktarda yă içerdiğinden dolayı GO ve MGO'nun biyoerişilebilirliğinin lipid peroksidasyonuna bağlı olarak arttığı düşünülmektedir.

Süt örneklerinde sindirim öncesi ölçülen $\mathrm{GO}$ ve $\mathrm{MGO}$ miktarı sirasiyla 62 ve $114 \mu \mathrm{g} / 100 \mathrm{~g}$, ve 19 ve $43 \mu \mathrm{g} / 100 \mathrm{~g}$ arasında bulunmuştur. Ekitet üzerinde beyan edilen yağ miktarı ise 1,5 ile $3,1 \mathrm{~g} / 100 \mathrm{~g}$ arasında değişmektedir. GO ve MGO'nun biyoerişilebilirliği sırasıly $\% 10$ ile $\% 25$, ve $\% 18$ ile $\% 39$ arasında değişmektedir. Süt örneklerinin biyoerişilebilirliği diğer gıdalarda göre karşılaştırıldığında daha düşük olduğu görülmektedir. Süt proteinlerinde vitamin (Yaman vd. 2019) ve mineral (Vegarud vd. 2000) bağlayıcı proteinler gibi birçok bağlayıcı protein bulunmaktadır. Örneğin, folat bağlayıcı e-ISSN: $2148-2683$ proteinler, bağırsak bakterilerine karşı koruma sağlamak için folatı bağlamaktadırlar. Sütte bulunan bağlayıcı proteinlerin GO ve MGO'yu bağlandığı ve dolayısıyla biyoerişilebilirliği azaltığı düşünülmektedir.

Papetti vd. (2013) balzamik sirkesinde bulunan $\alpha$-dikarbonil bileşikleri olan GO ve MGO'un in vitro biyoerişilebilirliklerinin yaklaşık \%30 azaldığını raporlamıştır. Bu çalışmada sindirim enzimlerinin varlığında $\alpha$-dikarbonil bileşiklerinin AGE bileşiklerine dönüştüğünden dolayı biyoerişilebilirliğin azaldığı raporlanmıştır. Başka bir çalışmada yine sindirim sırasında $\alpha-$ dikarbonil bileşiklerinin proteinlerle reaksiyona girdiği ve AGE'lerin oluş̧uğunu bildirmiş̧tir (Yang vd. 2011). MartinezSaez vd. (2019) serbest amino asitlerin in vitro ortamda glukoz ve fruktoz ile reaksiyona girerek Maillard reaksiyon ürünlerinin oluştuğunu bildirmiş̧ir. Sindirim sırasında proteinler ve nişasta enzimler tarafindan hidrolize edilir. Proteinlerden serbest amino asitler ve nişastada ise serbest şekerler salınmaktadır. Aynı çalışmada sindirim sırasında oluşan reaktif serbest amino asitlerin reaktif karbonil gruplarıla reaksiyona girmesiyle CML ve CEL gibi AGE'lerin oluştuğu bildirilmiştir. Başka bir çalışmada ise in vitro ortamda kahvede GO, MGO ve DA'nın in vitro biyoerişilebilirliği sırasıyla \%74, \%29 ve \%67 oranında azaltılmıştır (Papetti vd. 2014). Benzer şekilde sindirim 
proteinleri ile $\alpha$-dikarbonil bileşiklerinin in vitro ortamda reaksiyona girdiği ve AGE son ürünlerinin oluştuğu ve bu nedenle $\alpha$-dikarbonil bileşiklerinin biyoerişilebilirliğinin azaldığ bildirilmiştir. Aynı çalışmada soya sosunda GO ve MGO'un in vitro biyoerişilebilirliği \%290 ve \%1000 olarak bulunmuştur. $\mathrm{Bu}$ artışın nedeni olarak gıda içindeki farklı matrikslerin biyoerişilebilirliği arttırabileceği bildirilmiştir. Çalışmamızda görüldüğü gibi GO ve MGO'nun in vitro biyoerişilebilirliği bisküvi, cips ve kahvaltılık gevreklerde genel olarak \%100'ün üzerinde bulunmuştur.

Gıdalarda in vitro ortamda yağların oksidasyona uğramasıyla reaktif $\alpha$-dikarbonil bileşiklerinin oluştuğu düşünülmektedir. (Hidalgo vd. 2016; Yu vd. 2016; Zamora ve Hidalgo, 2011). Mariutti vd. (2017) lipidlerin oksidasyonunun hem enzimatik hem de enzimatik olmayan ortamda tuz ilavesiyle ve oksijen varlığında oluşabileceğini bildirmiştir. Sodyum klorür anti-mikrobiyal gıda katkı maddesi olarak kullanılır. Tuz ilavesi antioksidan enzimlerin aktivitesini azaltmaktadır. Bilindiği gibi anti-oksidan enzimler lipid oksidasyonunu engeller (Mariutti vd. 2017). Bu çalışmada görüldüğü gibi tuz içeren gıdalarda tuzun antioksidan enzimlerin aktivitesini azaltacağından dolayı lipid oksidasyonun artacağı ve böylece $\alpha$-dikarbonil bileşiklerinin in vitro iyoerişilebilirliğinin artabileceği düşünülmektedir.

$\mathrm{Bu}$ çalışmanın sonuçlarından da görüldüğü gibi tuz ve yağ birlikte in vitro gastrointestinal sistemde reaktif $\alpha$-dikarbonil olan GO ve MGO'nun miktarına arttırdığı düşünülmektedir. Polifenoller, vitaminler, kateşinler ve proantosiyaninler gibi bazı antioksidanlar gidalarda reaktif $\alpha$-dikarbonil bileşikleri ve AGE'lerin oluşumunu engelleyebileceği bildirilmiştir ( $\mathrm{Wu}$ ve Yen, 2005; Peng vd. 2010). Yağ ve tuz içeren gidaların antioksidanlar ile birlikte tüketilmesi in vitro ortamda da $\alpha$ dikarbonil bileşiklerinin oluşumunu engeleyebileceği düşünülmektedir. Dolayısıyla gelecekte bu düşünceyi destekleyici çalışmalara ihtiyaç vardır.

\section{Sonuç}

Maillard reaksiyon ürünleri hem gıda işleme sırasında hem de insan vücudunda AGE'lerin oluşumuna neden olmaktadır. Bilindiği gibi AGE'lerin en güçlü öncüleri olan GO ve MGO lizin, arginin ve histidin gibi reaktif amino asitlerle reaksiyona girerek AGE'leri oluşturmaktadır. $\mathrm{Bu}$ zararlı AGE bileşikleri kardiyovasküler hastalıklarına, Alzheimer hastalığına ve diyabetikin komplikasyonlarına neden olabilmektedir. Literatürde GO ve MGO'nun biyoerişilebilirliği hakkında sınırlı çalışma bulunmaktadır. Bu çalışmada süt hariç diğer gıdalarda GO ve MGO'un in vitro biyoerşilebilirliğinin genel olaral arttığ görülmüştür. Yüksek yağ ve tuz in vitro ortamda lipidlerin peroksidasyonuna neden olabileceği ve ve bunun sonucunda $\alpha$ dikarbonil bileşiklerinin oluşabileceği düşünülmektedir. Gıdalardaki yağ, tuz ve serbest şeker içeriğinin azaltılması in vitro gastrointestinal sistemde daha düşük GO ve MGO oluşumunu sağlayabilir. $\mathrm{Bu}$ sonuçları desteklemek için yeni çalışmalara ihtiyaç vardır.

\section{Teșekkür}

$\mathrm{Bu}$ çalışma İstanbul Sabahattin Zaim Üniversitesi ARGE laboratuvarlarında tamamlanmıştır. Desteklerinden dolayı İstanbul Sabahattin Zaim Üniversitesi'ne teşekkür ederiz.

\section{Kaynakça}

Amrein, T. M., Andres, L., Manzardo, G. G., \& Amadò, R. (2006). Investigations on the promoting effect of ammonium hydrogencarbonate on the formation of acrylamide in model systems. Journal of agricultural \& food chemistry, 54(26), 10253-10261.

Cengiz, S., Kişmiroğlu, C., Cebi, N., Catak, J., \& Yaman, M. (2020). Determination of the most potent precursors of advanced glycation end products (AGEs) in chips, crackers, and breakfast cereals by high performance liquid chromatography (HPLC) using precolumn derivatization with 4-nitro-1, 2-phenlenediamine. Microchemical Journal, 158, 105170 .

Henle, T. (2005). Protein-bound advanced glycation end products (AGEs) as bioactive amino acid derivatives in foods. Amino acids, 29(4), 313-322.

Hidalgo, F. J., León, M. M., \& Zamora, R. (2016). Amino acid decarboxylations produced by lipid-derived reactive carbonyls in amino acid mixtures. Food chemistry, 209, 256261.

Hrynets, Y., Ndagijimana, M., \& Betti, M. (2015). Studies on the formation of Maillard and caramelization products from glucosamine incubated at 37 C. Journal of agricultural $\&$ food chemistry, 63(27), 6249-6261.

Luevano-Contreras, C., \& Chapman-Novakofski, K. (2010). Dietary advanced glycation end products and aging. Nutrients, 2(12), 1247-1265.

Mariutti, L. R., \& Bragagnolo, N. (2017). Influence of salt on lipid oxidation in meat and seafood products: A review. Food Research International, 94, 90-100.

Martinez-Saez, N., Fernandez-Gomez, B., Cai, W., Uribarri, J., \& del Castillo, M. D. (2019). In vitro formation of Maillard reaction products during simulated digestion of mealresembling systems. Food Research International, 118, 72-80.

Nowotny, K., Jung, T., Höhn, A., Weber, D., \& Grune, T. (2015). Advanced glycation end products and oxidative stress in type 2 diabetes mellitus. Biomolecules, 5(1), 194-222.

Papetti, A., Mascherpa, D., \& Gazzani, G. (2014). Free $\alpha$ dicarbonyl compounds in coffee, barley coffee and soy sauce and effects of in vitro digestion. Food chemistry, 164, 259265.

Papetti, A., Mascherpa, D., Marrubini, G., \& Gazzani, G. (2013). Effect of In Vitro Digestion on Free $\alpha$-Dicarbonyl Compounds in Balsamic Vinegars. Journal of food science, 78(4), 514-519.

Peng, X., Ma, J., Cheng, K. W., Jiang, Y., Chen, F., \& Wang, M. (2010). The effects of grape seed extract fortification on the antioxidant activity and quality attributes of bread. Food Chemistry, 119(1), 49-53.

Poulsen, M. W., Hedegaard, R. V., Andersen, J. M., de Courten, B., Bügel, S., Nielsen, J.,Skibsted, L. H., \& Dragsted, L. O. (2013). Advanced glycation endproducts in food and their effects on health. Food \& Chemical Toxicology, 60, 10-37.

Rabbani, N., \& Thornalley, P. J. (2014). The critical role of methylglyoxal and glyoxalase 1 in diabetic nephropathy. Diabetes, 63(1), 50-52.

Richmond, M. L., Brandao, S. C., Gray, J. I., Markakis, P., \& Stine, C. M. (1981). Analysis of simple sugars and sorbitol in fruit by high-performance liquid chromatography. Journal of agricultural \& Food chemistry, 29(1), 4-7. 
Sansano, M., Heredia, A., Peinado, I., \& Andrés, A. (2017). Dietary acrylamide: What happens during digestion. Food chemistry, 237, 58-64.

O'Brien, J., Nursten, H. E., Ames, J. M., Crabbe, M. J. C., \& Crabbe, J. (Eds.). (1998). The Maillard reaction in foods and medicine (Vol. 223). Woodhead Publishing.

Uribarri, J., Woodruff, S., Goodman, S., Cai, W., Chen, X., Pyzik, R., Yong, A., Striker, G.E., \& Vlassara, H. (2010). Advanced glycation end products in foods and a practical guide to their reduction in the diet. Journal of the American Dietetic Association, 110(6), 911-916.

Vegarud, G. E., Langsrud, T., \& Svenning, C. (2000). Mineralbinding milk proteins and peptides; occurrence, biochemical and technological characteristics. British Journal of Nutrition, 84(1), 91-98.

Wu, C. H., \& Yen, G. C. (2005). Inhibitory effect of naturally occurring flavonoids on the formation of advanced glycation endproducts. Journal of agricultural \& food chemistry, 53(8), 3167-3173.

Yaman, M., \& Mizrak, Ö. F. (2019). Determination and evaluation of in vitro bioaccessibility of the pyridoxal, pyridoxine, and pyridoxamine forms of vitamin B6 in cereal-based baby foods. Food chemistry, 298.

Yaman, M., Mızrak, Ö. F., Çatak, J., \& Sargın, H. S. (2019). In vitro bioaccessibility of added folic acid in commercially available baby foods formulated with milk and milk products. Food Science and Biotechnology, 28(6), 1837-1844.

Yaman, M., Çatak, J., Uğur, H., Gürbüz, M., Belli, İ., Tanyıldız, S. N.,\& Yaldı, M. C. (2021). The bioaccessibility of watersoluble vitamins: A review. Trends in Food Science \& Technology.

Yang, K., Qiang, D., Delaney, S., Mehta, R., Bruce, W.R., \& O'Brien, P.J. (2011). Differences in Glyoxal and methylglyoxal metabolism determine cellular susceptibility to protein carbonylation and cytotoxicity. ChemicoBiological Interactions, 191, 322-9.

Yu, L., He, Z., Zeng, M., Zheng, Z., He, J., Wang, M., \& Chen, J. (2016). Effects of oxidised linoleic acid on the formation of $\mathrm{N} \varepsilon$-carboxymethyl-lysine and Ne-carboxyethyl-lysine in Maillard reaction system. International journal of food science \& technology, 51(3), 742-752.

Zamora, R., \& Hidalgo, F. J. (2011). The Maillard reaction and lipid oxidation. Lipid Technology, 23(3), 59-62. 